Ильин М.С. Альтернативный исламский дискурс: автобиография как инструмент транссрормации представлений о религиозном атворитете // Технологос. - 2021. - № 1. - С. 112-121. DOI: 10.15593/perm.kipf/2021.1.10

Ilyin M.S. Alternative Islamic Discourse: Autobiography as a Tool for Transformation of Religious Authority. Technologos, 2021, no. 1, pp. 112-121. DOI: 10.15593/perm.kipf/2021.1.10

DOI: $10.15593 /$ perm.kipf/2021.1.10

УДК 28-055.2

АЛЬТЕРНАТИВНЫЙ ИСЛАМСКИЙ ДИСКУРС: АВТОБИОГРАФИЯ КАК ИНСТРУМЕНТ ТРАНСФОРМАЦИИ ПРЕДСТАВЛЕНИЙ О РЕЛИГИОЗНОМ АВТОРИТЕТЕ

\author{
М.С. Ильин \\ Манчестерский университет, Манчестер, \\ Соединенное Королевство Великобритании и Северной Ирландии
}

\section{O CTATbE}

Получена: 23 января 2021 г.

Принята: 10 марта 2021 г.

Опубликована: 15 апреля 2021 г.

\section{Ключевые слова:}

ислам, альтернативный дискурс, религиозный авторитет, религиозные нормы, автобиографический нарратив, гендерные движения, гендерная идеология, поведенческая модель.

\begin{abstract}
АННОТАЦИЯ
Статья построена на дискурсивном анализе автобиографических исламских нарративов, рассказывающих о практиках оспаривания мужского религиозного авторитета женщинами-мусульманками в Афрганистане и Ливии в конце XX - начале XXI века. В ходе исследования основное внимание уделяется речевым стратегиям авторов, которые являются инструментом для изменения общественных представлений о праве женщин на интерпретацию религиозных, политических, социальных практик. В качестве базового теоретического концепта предлагается рассмотреть альтернативный исламский дискурс, включающий в себя проблему гендерной идентификации в исламских сообществах. Представлена гипотеза о реализации современных практик оспаривания религиозной власти и авторитета женскими исламскими сообществами не на уровне доктринальных дискуссий, а в социальном, образовательном и культурных контекстах. Основной формат выступлений спикеров-мусульман представлен видеоматериалами, размещенными на открытых интернет-платформах. Рассматриваемые выступления авторов-мусульман, исходят из представления об идеологическом контроле над практикой интерпретации религиозных норм. Искажения в интерпретациях религиозных текстов и практик укоренялись в общественном сознании мусульман посредством традиций. Согласно представленным материалам, ведущую роль в ходе трансформации представлений оказывает институт образования. В рамках данного исследования под трансформацией общественных представлений понимается процесс, направленный на преодоление доминирования группой или отдельными персонами, осознающими свое исходное положение с позиции подчиненных. Особое внимание в статье уделяется представлению о власти как о субъектной позиции акторов и праве на реализацию поведенческих моделей в соответствии с требованиями современности.
\end{abstract}

\footnotetext{
(c) Ильин Максим Сергеевич - проектный партнер, Манчестерский институт исследований и инноваций в области искусства и дизайна (MIRIAD), ORCID: https://orcid.org/0000-0002-1960-8214, e-mail: maksi-ilin@yandex.ru.

(C) Maxim S. Ilyin - Project Partner, Manchester Institute for Art and Design Research and Innovation (MIRIAD), ORCID: https://orcid.org/0000-0002-1960-8214, e-mail: maksi-ilin@yandex.ru.
}

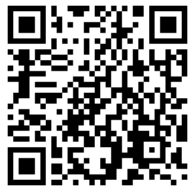

Эта статья доступна в соответствии с условиями лицензии Creative Commons Attribution-NonCommercial 4.0 International License (CC BY-NC 4.0)

This work is licensed under a Creative Commons Attribution-NonCommercial 4.0 International License (CC BY-NC 4.0) 


\title{
ALTERNATIVE ISLAMIC DISCOURSE: AUTOBIOGRAPHY AS A TOOL FOR TRANSFORMATION OF RELIGIOUS AUTHORITY
}

\author{
Maxim S. Ilyin
}

The University of Manchester, Manchester, The United Kingdom of Great Britain and Northern Ireland

\section{ARTICLE INFO}

Received: 23 January 2021

Accepted: 10 March 2021

Published: 15 April 2021

\section{Keywords:}

Islam, alternative discourse, religious authority, religious norms, autobiographical narrative, gender movements, gender ideology, behavioral model.

\begin{abstract}
The article is based on a discursive analysis of autobiographical Islamic narratives that tell about the practices of challenging male religious authority by Muslim women in Afghanistan and Libya in the late XX - early XXI centuries. The research focuses on the authors' speech strategies, which are a tool for changing public perceptions about the right of women to interpret religious, political, and social practices. As a basic theoretical concept, it is proposed to consider an alternative Islamic discourse, which includes the problem of gender identification in Islamic communities. This article presents a hypothesis that modern practices of challenging religious authority and authority by women's Islamic communities are implemented not at the level of doctrinal discussions, but in social, educational and cultural contexts. The main format of the speeches of Muslim speakers is presented by video materials posted on open Internet platforms. The speeches of the Muslim authors under consideration are based on the idea of ideological control over the practice of interpreting religious norms. Distortions in the interpretation of religious texts and practices have taken root in the public consciousness of Muslims through traditions. According to the presented materials the leading role in the transformation of ideas is played by the institution of education. Within the framework of this study the transformation of social ideas is understood as a process aimed at overcoming dominance by a group or individuals who are aware of their starting position from the position of subordinates. Particular attention is paid to the concept of power as a subjective position of actors and the right to implement behavioral models in accordance with the requirements of the present.
\end{abstract}

(C) PNRPU

Идея обращения к теме альтернативного исламского дискурса возникла в ходе исследования многообразного религиозного опыта представителей гендерного движения исламского феминизма конца XX - начала XXI века, мобилизующих виртуальные среды в качестве стратегии расширения эгалитарного дискурса применительно к исламской теологии и философии, современной исламской культуре, а также инструментам конструирования исламской идентичности [1, p. 4].

Для мусульманских сообществ России и постсоветского пространства проблематика исламского феминизма представляется чем-то удаленным, экзотичным, что очевидно связано с отсутствием условий для перехода от традиционного исламского дискурса к различным вариантам гендерного осмысления исламской культуры и его публичного позиционирования. В этом смысле достаточно показательным является интервью российской мусульманки Н. Тамбиевой для онлайн-журнала The Village «Как я пришла к исламскому феминизму» (от 22.05.2019) [2]. Интересно, что осуществляя исследовательскую практику исламских феминизмов в рамках академического дискурса, в своих ответах респондент не обращается к гендерному дискурсу. Вероятно, речь об исламском феминизме осуществляется с позиций традиционного исламского дискурса, различая категорию исламский феминизм скорее как академическую интенцию, а не социальную практику. Именно поэтому разговор об исламском феминизме как социальной практике, предполагающей различные модификации альтернативных дискурсов в России, остается открытым.

В контексте постколониального поворота, теоретической рефлексии, последующей академической полемики на протяжении 1990-х и начала 2000-х годов многие из исследователеймусульман (А. Барлас, А. Вадуд, Л. Ахмед и др.) отказались идентифицировать себя посредством категории исламский феминизм (феминизм как ориентальный академический концепт) [3, p. 11-20]. Прежде всего потому, что мусульманские женские сообщества лишались «воз- 
можности использовать собственное (локальное) местонахождение в целях самоопределения и самопрезентации» [4, с. 258]. Обращение к термину «альтернативный дискурс» замещает в данном исследовании дискуссионный концепт исламский феминизм, что представляется методологически оправданным, поскольку в отношении речевых стратегий женщин-мусульманок становится возможным объединить выступления спикеров на уровне авторских намерений - оспаривания символической власти исламских религиозных авторитетов (сохраняя децентрированнные позиции авторов). Продолжая в этом аспекте исследования С. Ольссон и К. Керстен [5, p. 4], Н. Саат [6, р. 4], воспользуемся термином альтернативныий исламский дискурс, понимая под ним многообразие внеинституциональных речевых стратегий, направленных прежде всего на оспаривание нормативных оснований власти, исключительного права интерпретации религиозной и иных практик вне зависимости от позиции властных институтов.

Основываясь на исследовательских материалах ближневосточных кейсов, А. Гонсалес отмечает, что одной из важнейших особенностей социумов, базирующихся на исламских нормах, является неотделимость религиозного, политического и культурного общественных измерений, в совокупности образующих легитимность властного контроля над этим социумом [7, p. 16-17]. Следовательно, критическая установка в отношении любого из компонентов этих измерений неизменно приводит в конечном счете с одной стороны, к экстраполяции критики в отношении легитимности властного контроля в целом, с другой - к усилению санкций властного контроля в отношении источника альтернативного дискурса.

Цель данной статьи - рассмотреть через призму критического дискурс-анализа речевые стратегии альтернативного дискурса в автобиографических нарративах женщин-мусульманок как инструмент трансформации общественных представлений о религиозном авторитете.

\section{История альтернативного гендерного дискурса: революции, агентство, преодоление фундаментализма}

История альтернативных исламских гендерных дискурсов, трансформирующих ролевые модели поведения мусульманок, представляется закономерным отражением политической трансформации в ряде государств Ближнего Востока второй половины XX века. Так, например, иранское общество обладало опытом участия как в Иранской революции 1978-1979 годов (включая опыт «Исламской культурной революции»), так и Ирано-Иракской войны 1980-1988 годов.

Анализируя проблему влияния революционного контекста на политическую и религиозную активность женщин в Иране конца 1980-х - начала 1990-х годов, антрополог А. Шамс предлагает различать в их дискурсивной самоидентификации проявления «революционной религиозности» («mazhabi-yi enqilabi») и «традиционной религиозности» («mazhabi-yi ma`muli») [8, p. 40].

Под «революционной религиозностью» предлагается понимать совокупность мировоззренческих установок и практик, воплощающихся посредством представлений о религиозном и национальном долге, преодолевающем патриархальные ограничения [8, p. 41]. Одним из важнейших следствий исламизации Иранской республики, по мнению А. Шамс, является проявившаяся женская гомосоциальность, которая основывается на религиозных нормах и вступает в противоречие с секулярной гетеросоциальностью (период правления Мохаммеда Реза Пехлеви - 1941-1979 годы). Необходимо пояснить, что сокращение дистанции между публичным и частным пространствами в ходе революции, на уровне коллективных представлений, позволило экстраполировать женские обязательства в сферу государственной деятельности. То есть «революционная религиозность» способствовала мобилизации женской религиозности и агентства в аспекте легитимизации права на преобразовательную деятельность, а 
гомосоциальность, разрушая классовые границы и барьеры между женщинами, позволяла им сообщаться и создавать сообщества и движения [8, p. 42-44].

Несколько схожим выглядит появление альтернативных исламских дискурсов в Кувейте, Бахрейне, Катаре и других государствах Персидского залива. Например, исламистский дискурс в Кувейте начала 1990-х годов и деятельность исламистских политических организаций (аль-Ихван аль Муслимун / «Братья мусульмане») в значительной степени мобилизовали женщин-мусульманок к активному политическому участию (женские комитеты - «lijân nisâ'iah») [9, p. 43-44]. Впоследствии, когда женские сообщества отходят от исламисткого дискурса, их общественная активность не исчезает, консолидируясь вокруг проблемы расширения прав женщин посредством альтернативных исламских дискурсов [9, p. 46].

Как отмечает X. аль-Мугни, среди влиятельнейших исламских интеллектуалов и активистов в Кувейте выделяются такие фигуры, как Х. аль-Махмит, Х. аль-Атик и У. аль-Рифаи, повлиявшие на конструирование альтернативного исламского дискурса и критику исламисткого дискурса в части гендерной проблематики [10, p. 21-23]. Попробуем представить ключевые идеи женщин-мусульманок, нашедшие отражение в альтернативных исламских дискурсах конца XX - начала XXI века:

1) интерпретация религиозных / священных текстов может осуществляться только в аутентичном понимании смыслов, полученных во времена пророчества Мохаммада, и имеет целью достижение справедливого исламского общества;

2) получение прав женщинами возможно через совершение иджтихада для устранения приписываемых традицией ценностей;

3) понятие «an-Nahda» / «возрождение», «пробуждение» - предполагает восстановление субъектного и автономного статуса женщины как личности и полноправного члена социума;

4) исламское государство должно включать в себя две характеристики: конституционность и гражданственность, обеспечивающие права человека и общества;

5) переосмысление концепции «al-wilayah al-'ammah» / «общих полномочий» / «руководства уммой» предполагает возможность приобретения политических прав для женщин.

Таким образом, альтернативный исламский дискурс является своего рода результатом глубокого переосмысления исламисткого дискурса в аспекте прав мусульманок, функционировавшего в постреволюционных и поствоенных условиях бытования исламских женских сообществ конца второй половины XX века. А представленные ранее идеи крайне важны для понимания исламских автобиографических нарративов, которые будут представлены в данной статье.

\section{Автобиография как стратегия гендерной самопрезентации}

Опыт конструирования нарратива как автобиографии является достаточно распространенным среди представителей исламского гендерных движений и возникает значительно раньше возможности применения медийных / онлайновых инструментов коммуникации с целью распространения альтернативных (как традиционному, так и ориентальному дискурсу) взглядов (так называемое «двойное агентство» автора) [11, р. 28]. Стоит помнить, что ранее авторы обращались к своему адресату в условиях действия религиозной и политической цензуры, а практика публичного позиционирования могла обернуться тяжелыми последствиями как для самого автора, так и его адресата (например, Ф. Мернесси, 3. аль-Газали, Д. Шафик) $[12$, p. 44]. В какой-то степени нормативный контроль над общественной сферой в ряде государств Ближнего Востока актуализировал расширение альтернативных дискурсов в киберпространствах $[13$, p. 31]. С появлением блогосферы и дигитализацией коммуникаций в странах 
Ближнего Востока возможности для реализации различных стратегий в области религиозной, политической и иных типов идентичности существенно изменились (многообразие индивидуальных религиозных поликодовых платформ) [14].

Понимание контекста функционирования автобиографического нарратива позволило исследователям сформировать устойчивое историографическое представление об автобиографии как многослойном источнике, требующем особого подхода (например, теория «многократной критики» М. Куук; метод «возвращения вытесненного» С.С. Фридман) [15]. Поскольку автобиография подразумевала работу с критическими стратегиями автора на уровне подтекста, то от исследователя требовалась концентрация, прежде всего, не на поверхностных, а на глубинных уровнях послания [6, p. 44]. Другими словами, не только на содержании повествования, но и способах / каналах передачи автобиографического сообщения.

\section{Альтернативная стратегия нового религиозного лидерства А. Хана}

В 2016 году появилось исследование К. Петерсон, которое на примере критического дискурс-анализа «YouTube» - канала блогера-мусульманки Амины Хана презентовало новую модель изучения религиозного лидерства посредством виртуального автобиографического нарратива. Вывод, представленный в исследовании К. Петерсон, крайне важен: современные практики оспаривания религиозной власти, религиозного авторитета происходят не на уровне доктринальных дискуссий, а в социальных, культурных и экономических полях. Возвращая адресанту символическую власть мнения и реализацию поведенческой модели, сетевое сообщество через инструменты обратной связи начинает разделять установки адресанта [16, p. 18-26].

В данном случае важно понять: во-первых, являются ли выводы К. Петерсон относительно кейса А. Хана отдельным прецедентом в рамках альтернативного исламского дискурса; вовторых, можно ли говорить об общей механике воздействия медийных автобиографических нарративов как общего механизма дискурсивного оспаривания религиозного авторитета?

Представленный в исследовании К. Петерсон кейс является одним из примеров видеохостинга, т.е. медийного источника, функционирующего на базе общедоступной виртуальной платформы (сайта или канала). Следовательно, для того чтобы ответь на поставленные ранее вопросы, необходимо обратиться к типологически близким медийным источникам.

\section{Критический дискурс-анализ исламского автобиографического нарратива}

В качестве кейса данного исследования предлагается рассмотреть видеовыступления, размещенные на виртуальной платформе некоммерческого фонда TED (Technology Entertainment Design) в соответствии с критериями кейса К. Петерсон (общедоступность материалов; спикеры, исповедующие ислам; автобиографическая форма нарратива). В качестве методологии анализа к автобиографическим нарративам применялась программа критического дискурс анализа Т. Ван Дейка [17].

История С. Йакууби How I Stopped the Taliban from Shutting Down My School [18] - автобиографический нарратив, повествующий об оспаривании религиозного авторитета в Афганистане в период контроля над страной исламистского движения «Талибан» (вторая половина 1990-х - начало 2000-х годов). В нарративе «Талибан» представлен как коллективный антигерой, присваивающий право интерпретации религиозных норм на основе насильственных действий.

Процесс трансформации антигероя в нарративе состоит из трех компонентов:

1. Условия («...вы принимаете все, что я вам скажу»; «... привела их в мечеть») - необходимо обратить внимание, что мечеть также выступает у автора как пространство транс- 
формации, как место, где антигерой возвращается к одному из исходных смыслов ислама как помощи, уходя от доминирующей деструктивной практики.

2. Процесс как действия («они сказали»; «они согласились»; «...они учат ... они учатся»; «они изучают») - на этой стадии автор расширяет характеристику внерелигиозного знания необходимого для трансформации («как быть учителями ... изучают компьютеры ... английский язык»).

3. Последствия и результат («они - лучшие преподаватели»; «они - мои советчики»; «они идут впереди»; «они защищают нас») - фиксируют изменение мышления в темпоральном срезе (в «прошлом» и «настоящем»); антигерой получил трансформацию как деструктивный агент («...становятся другими») посредством образования (религиозное знание как установка на ценностном уровне и внерелигиозное знание как инструмент изменения контекста).

В макроструктуре «оценка» автор расширяет свою установку для адресата - гендерное равенство возможно только при изменении мышления как женщин, так и мужчин. Макроструктура «резолюция» дополняет эту установку, сообщая прагматические цели автора уже на уровне страны (Афганистан): безопасность, возможность личностной и профессиональной реализации. Прагматическая цель нарратива в таком случае предполагает и совет, и побуждение к действию, и ожидание эмоциональной реакции адресата. В макроструктуре «резолюция» автор указывает на воспроизводимость своего опыта («... я уверена на сто процентов, что каждый сможет сделать это в любом уголке мира»), что предполагает усиление актуализации информации для адресата. Реакция аудитории (смех, аплодисменты, взгляды, сосредоточенность лиц, мимика) по ходу наррации указывает в первую очередь на осуществление условий успешной референции между адресантом и адресатом, что позволяет судить и об успешности коммуникации в ходе наррации.

Подводя итоги анализа истории, следует обратить внимание на презентацию ментальной модели автора (контекст). Нарратив С. Йакууби представляет последовательность ситуационных моделей (в данном случае локаций), задействующих фоновые знания аудитории (адресата) посредством общедоступных универсальных фреймов: детство, война, лагерь беженцев, образование, школа, терроризм и т.д. Используя реверсивный режим презентации (когда описываемые ситуационные модели фокусируются в точке осознания контраста или конфликта между собственными представлениями адресата об этих фреймах и теми ситуациями, что обозначает автор) эксплицитных локальных ситуационных моделей автор достигает опознавания, схватывания адресатом универсальных, знакомых ему посредством фоновых знаний сценариев. Обращение автора к такой стратегии (аналогия референтных ситуаций) позволяет адресату выявлять имплицитную информацию (то, на что указывает, отсылает, направляет автор), связывая локальные ситуационные модели (Афганистан, Пакистан - ситуация глокализации) с установками глобального уровня дискурса (международное право, права человека, демократия, образование). Создав на всех уровнях нарратива аргументативные конструкции, автор сопровождает их примерами и иллюстрациями, где антигерой действует исключительно деструктивными методами, достигая только деструктивных последствий (насилие, убийства, избыточное доминирование). Опознавание адресатом этих последствий через фоновые знания приводит к отрицанию подобных перспектив и соглашению с позицией автора. Достижение финальной сцены, успешность истории в следствиях, установка на воспроизводимость опыта автора возвращают адресата обратно - к аргументативным конструкциям, усиливая их в каждом отдельном случае. Особую роль в этом случае приобретает усиление воздействия на эмоционально-психологическое состояние адресата. Обращаясь к альтернативному дискурсу как инструменту мобилизации для агентов нарратива и инструменту презентации достоверности авторской позиции для адресата, С. Йакууби иллюстрирует две альтернативные стратегии (героя и антигероя). Первая из них 
трансформационная (изменения в мышлении, поведении, действиях) представляет позитивные следствия, в то время как вторая, деструктивная - исключительно разрушительные последствия. Необходимо обратить внимание на еще одну важную импликатуру: очевидно, что только религиозного знания недостаточно для трансформации условий - С. Йакууби выступает за конвергенцию религиозных и внерелигиозных знаний. Таким образом, автор:

а) отчуждает право антигероя на власть посредством оспаривания контроля со стороны антигероя;

б) устраняет ситуацию неравенства;

в) создает новый уровень понимания авторитета (и для женщин, и для мужчин).

Оспаривание контроля достигается С. Йакууби путем рассмотрения личного опыта в тесной связи с обществом в целом и страной, что позволяет говорить от имени общества и страны (стратегия сверхобобщения). Так, в нарративе реализуется генерализация противопоставления (имплицитное, переходящее в эксплицитное) между действиями движения Талибан и будущим Афганистана.

История Ш. Басидж-Раших Dare to Educate Afghan Girls [19] приводится в данном кейсе как нарратив, который имеет устойчивые связи с историей С. Йакууби (в сочетании эти нарративы образуют своего рода «афганский» микрокейс - идентичную нарративную ситуацию, представленную с различных позиций и в разных ролях). Нарратив Ш. Басидж-Раших предполагает обратную перспективу. Если история С. Йакууби презентует ее действия как агента, инициирующего прецедент создания школы как центра трансформационных изменений, то Ш. Басидж-Раших - агент, обладающий опытом образования в одной из «подпольных» школ Афганистана. Между представленными нарративами нет прямой связи (личное знакомство, упоминания авторами друг друга, обозначения «общих» локаций), что вместе с тем позволяет предположить хронологическое совпадение между описываемыми событиями и косвенную общность осложняющих нарративы условий.

В отличие от нарратива С. Йакууби, где герой сталкивается с талибами напрямую, «осложнение истории» у Ш. Басидж-Раших транслируется как опыт одной из учениц и ее отца («... едва не были убиты взрывом бомбы»; «если он ещзе раз отправит дочь в школу - они снова попытаются их убить»). Передача автором чужого высказывания (отца девушки) посредством прямой речи усиливает макроструктуру «оценка», придавая статус истинного и достоверного сообщения. Следует обратить внимание на речевую конструкцию, используемую агентом: «Убейте меня, ...если хотите ... но я не собираюсь...»). В данном случае, возможно, следует вывести следующую импликатуру: оспаривание внешнего нормативного контроля может осуществляться посредством его игнорирования. По сути, в нарративе не представлены авторские стратегии макроструктуры «решения», что вероятно, предполагает перспективу самостоятельной импликации адресатом. Таким образом, действия героя не противопоставлены антигерою, присутствующему в тексте косвенно - через авторские указания, - а развиваются параллельно контексту, как практика воспроизведения ценностных установок семейного опыта.

Используя стратегию контраста, автор создает два контрастных образа времени:

1) образ времени талибов (выступает как фрагмент макроструктуры «оценка» - «я была ... разочарована в жизни ... находилась в постоянном страхе ... не видела будущего ... хотелось все бросить»; «...ваших устаревших и отстальх убеждений»; «девочек посещавших школу было несколько сотен»);

2) образ времени образования («...я вижу перспективное будущее ...долговременные изменения»; «более трех миллионов девушек ходят на занятия в школь»»).

В первом случае отсутствует образ будущего как таковой, а во втором - время несет качественные изменения. Очевидно, что эта стратегия направлена на усиление всей аргументатив- 
ной конструкции нарратива, апеллируя к фоновым знаниям адресата. Как и в нарративе С. Йакууби, в макроструктурах «оценка» и «резолюция» у Ш. Басидж-Раших содержится схожая мысль: гендерное равенство возможно только в союзе с мужчинами («мы должны заручиться поддержкой мужчин»). Макроструктура «резолюция», как и в предшествующей истории, содержит стратегию обобщения (в обоих случаях авторы выходят на обобщение своего опыта до уровня страны - Афганистана, однако в перспективе С. Йакууби - это достигнутый результат, а в случае Ш. Басидж-Раших - ожидание и надежда). В отличие от предшествующей истории, в авторской резолюции проявляются черты постколониальной позиции (например, «... часто игнорируется на Западе»; «Из Америки Афганистан выглядит совершенно иначе»).

\section{Заключение}

Представленный в статье дискурсивный анализ автобиографических нарративов С. Йакууби и Ш. Басидж-Раших позволяет вернуться к вопросу о влиянии альтернативного дискурса на трансформацию представлений о роли религиозного авторитета.

Как следует из анализа, альтернативный дискурс конструируется авторами как свершившаяся, законченная коммуникация между различными ценностными системами, представленными двумя линиями - героя и антигероя. Обе линии имеют ярко выраженную аксиологическую, биполярную оценку с точки зрения последствий действий героя / антигероя - позитивно-трансформационную (обучение, помощь, строительство, развитие) и деструктивную (насилие, давление, ограничения, отсутствие перспективы для изменений). Эта логика реализуется посредством речевой стратегии контраста, обеспечивающей герою легитимное право оспаривать сложившийся порядок, поддерживаемый силой традиции или правом интерпретации религиозной нормы. Поскольку цель автора - достижение справедливого исламского общества, то привести к этой справедливости могут исключительно позитивно-преобразовательные действия (действия для общества, единоверцев). В силу того что антигерой не обладает потенциалом достигнуть справедливого общества (в нарративах С. Йакууби и Ш. БасиджРаших иллюстрируется на примере действий талибов), его власть условна и может оспариваться, даже если обладает фактическими инструментами контроля и принуждения. Особую роль в данном случае приобретает стратегия иронии, позволяющая автору на примере героя преодолевать ситуацию страха перед лицами, обладающими правом насилия в силу «присвоенной» религиозной нормы. Именно в этом моменте, по мысли авторов, возникает право героя нарратива на совершение иджтихада с целью преодоления деструктивных ситуаций, которые обусловливаются предписываемыми традицией ценностями.

Риторическая стратегия сверхобобщения завершает конструирование генерализации оспаривания власти - герой действует от имени мусульман как полноправный член социума, солидаризирующего цели социума и героя нарратива. Такой ход позволяет автору пересмотреть основания властвования - теперь власть основывается на ценности признания позитивных действий в интересах общества, а религиозный авторитет - это субъект, обеспечивающий эти изменения в интересах исламского социума. Следовательно, феномен религиозного авторитета в эпистемологии альтернативного исламского дискурса не следует интерпретировать как возможность осуществлять практику альтернативного руководства - скорее как обретение субъектности через реализацию представлений об исламском благочестии, поведении в соответствии с религиозной нормой, а не традицией интерпретации этой нормы.

Анализ представленных нарративов, позволяет с уверенностью утверждать, что исследовательский кейс К. Петерсон не является уникальным прецедентом, а воспроизводит об- 
щую модель альтернативного исламского дискурса вне зависимости от ситуационных моделей, описываемых авторами автобиографических нарративов. Данное утверждение позволяет сделать несколько важных макровыводов.

Во-первых, необходимо пояснить, что феномен власти в эпистемологии альтернативного исламского дискурса не следует интерпретировать как возможность осуществлять практику альтернативного руководства - скорее как обретение субъектности через реализацию представлений об исламском благочестии, поведении в соответствии с религиозной нормой, а не традицией интерпретации этой нормы.

Во-вторых, цель трансформации представлений о религиозном авторитете как процессе подразумевает не замещение в оппозиции «подчиненные» - «доминирующие» (через практику сопротивления), а снятие этой оппозиционности как таковой (например, трансформация антигероя в нарративе С. Йакууби).

В-третьих, обозначенная оппозиция является дифференцированной и не предполагает строгого обособления гендерных позиций. Только с учетом этих особенностей речь может идти об исследовании нарративных и дискурсивных стратегий женщин-мусульманок, осознавших результацию неравенства и стремящихся реализовать идею позитивности социальных изменений (в риторике, практиках, семиотических выражениях), обратившись к трансформации практик исламской духовной традиции и экстраполируя этот опыт на различные области коммуникации.

\section{Список литературы}

1. Latte S. Le feminisme islamique, vingt ans apres: economie d'un debat et nouveaux chantiers de recherche // Critique internationale. - 2010. - No. 1 (№ 46).

2. «Как я пришла к исламскому феминизму». Петербурженка Наталья Тамбиева - о женском клубе для мусульманок и реакции специалистов по исламу (интервью от 22.05.2019) // Интернет-журнал «The Village». - URL: https://www.the-village.ru/people/experience/350759islam-women (дата обращения 18.01.2021).

3. Saleh A. Paradigms of Knowledge in Islamic Feminism // Feminist and Islamic Perspectives. New Horizons of Knowledge and Reform. Ed. by: Omaima Abou-Bakr. Women and Memory Forum, 2013. - P. 11-20.

4. Бахманн-Медик Д. Культурные повороты. Новые ориентиры в науках о культуре / пер. с нем. С. Ташкенова. - М.: НЛО, 2017.

5. Olsson S., Kersten C. Alternative Islamic Discourses and Religious Authority (1st ed.). Routledge. 2016. - URL: https://doi.org/10.4324/9781315566603.

6. Saat N. The Politics of Islamic Discourse in Malaysia // Alternative Voices in Muslim Southeast Asia: Discourses and Struggles. - ISEAS - Yusof Ishak Institute, 2019.

7. Gonzalez A. Islamic Feminism in Kuwait. - New York: Palgrave Macmillan, 2013.

8. Shamsaei M. Iranian Religious Intellectuals and the Modernization Debate // Journal of Humanities and Social Science (IOSRJHSS). July-August, 2012. - Vol. 1, iss. 1. - P. 40-44.

9. Al-Mughni H. The rise of islamic feminism in Kuwait // Journal Revue des mondes musulmans et de la Méditerranée [Online], 128 | December 2010, Online since 05 January 2012, connection on 30 April 2018. - URL: https://journals.openedition.org/remmm/6899 (accessed 03 January 2020).

10. Al-Mughni H. Women's organizations in Kuwait // Journal Middle East Research and Information Project. MER 198 - Gender and citizenship in the Middle East. - URL: https://www.merip. org/mer/mer198 (accessed 03 January 2020).

11. Seedat F. Islam, Feminism, and Islamic Feminism: Between Inadequacy and Inevitability // Journal of Feminist Studies in Religion. - 2013. - Vol. 29, no. 2 (Fall). 
12. Tijani O.I. Raising Feminist Consciousness through Literature: Two Female Texts from the Arabian Gulf. J. Arab. Stud. 2019.

13. Tohamy A. Youth Activism and Social Networks in Egypt // CyberOrient. - 2017. - Vol. 11, iss. 1. - URL: http://www.cyberorient.net/article.do?articleId=9815 (accessed 14 December 2020).

14. Tschirhart Ph. The Saudi Blogosphere: Implications of New Media Technology and the Emergence of Saudi-Islamic Feminism // CyberOrient. - 2014. - Vol. 8, iss. 1. - URL: http://www.cyberorient.net/article.do?articleId=8864 (accessed 14 December 2020).

15. Abdo D.M. Narrating Little Fatima: A Picture is Worth 1001 Tales // «Multiple Critique» in Fatima Mernissi's Dreams of Trespass: Tales of a Harem Girlhood. Image [\&] Narrative [e-journal]. - 2007. Vol. 19. - URL: http://www.imageandnarrative.be/inarchive/autofiction/abdo.htm (accessed 18 January 2021).

16. Peterson K. Performing Piety and Perfection: The Affective Labor of Hijabi Fashion Videos // CyberOrient. - 2016. - Vol. 10, iss. 1. - URL: http://www.cyberorient.net/article.do?Article Id=9759 (accessed 18 November 2016).

17. Дейк Ван Т. Дискурс и власть: репрезентация доминирования в языке и коммуникации / пер. с англ. Кожемякина Е.А., Переверзева Е.В., Аматова А.М. - М., 2013.

18. Yacoobi S. «How I Stopped the Taliban from Shutting Down My School». - URL: https://www.ted.com/talks/sakena_yacoobi_how_i_stopped_the_taliban_from_shutting_down_my_s chool/transcript?language $=$ en\#t-136180 (accessed 18 November 2020).

19. Basij-Rasikh S. «Dare to Educate Afghan Girls». TED Talks. - URL: https://www.youtube. com/ watch?v=Ka70-Hb1wFE (accessed 08 March 2021).

\section{References}

1. Latte S. Le feminisme islamique, vingt ans apres: economie d'un debat et nouveaux chantiers de recherche. Critique international, 2010, no. 1 (№ 46).

2. «Kak ia prishla k islamskomu feminizmu». Peterburzhenka Natal'ia Tambieva - o zhenskom klube dlia musul'manok i reaktsii spetsialistov po islamu (interv'iu ot 22.05.2019) ["How I came to Islamic feminism." Petersburg woman Natalya Tambieva - about a women's club for Muslim women and the reaction of specialists in Islam (interview dated 22.05.2019)]. The Village, available at: https:// www.the-village.ru/people/experience/350759-islam-women (accessed 18 January 2021).

3. Saleh A. Paradigms of Knowledge in Islamic Feminism. Feminist and Islamic Perspectives. New horizons of knowledge and reform. Ed. Omaima Abou-Bakr. Women and Memory Forum, 2013. pp.11-20.

4. Bachmann-Medic D. Cultural turns. New landmarks in the sciences of culture. M., NLO, 2017, $258 \mathrm{p}$.

5. Olsson S., Kersten C. Alternative Islamic Discourses and Religious Authority (1st ed.). Routledge, 2016. DOI: https://doi.org/ $10.4324 / 9781315566603$

6. Saat N. The Politics of Islamic Discourse in Malaysia. Alternative Voices in Muslim Southeast Asia: Discourses and Struggles. ISEAS - Yusof Ishak Institute, 2019. p.4.

7. Gonzalez A. Islamic feminism in Kuwait. New York, Palgrave Macmillan, 2013, pp.16-17.

8. Shamsaei M. Iranian Religious Intellectuals and the Modernization Debate. Journal of Humanities and Social Science, 2012, vol. 1 , iss. 1 , pp. $40-44$.

9. Al-Mughni $\mathrm{H}$. The rise of islamic feminism in Kuwait. Journal Revue des mondes musulmans et de la Méditerranée, 128|December 2010, Online since 05 January 2012, connection on 30 April 2018, available at: https://journals.openedition. org/remmm/6899 (accessed 03 January 2020).

10. Al-Mughni H. Women's organizations in Kuwait. Journal Middle East Research and Information Project. MER 198 - Gender and citizenship in the Middle East, available at: https://www.merip.org/mer/mer198 (accessed 03 January 2020).

11. Seedat F. Islam, Feminism, and Islamic Feminism: Between Inadequacy and Inevitability. Journal of Feminist Studies in Religion, 2013, vol. 29, no. 2, p. 28.

12. Tijani O.I. Raising Feminist Consciousness through Literature: Two Female Texts from the Arabian Gulf. J. Arab. Stud., 2019.

13. Tohamy A. Youth Activism and Social Networks in Egypt. CyberOrient, 2017, vol. 11, iss. 1, available at: http://www.cyberorient.net/ article.do?articleld=9815 (accessed 14 December 2020).

14. Tschirhart Ph. The Saudi Blogosphere: Implications of New Media Technology and the Emergence of Saudi-Islamic Feminism. CyberOrient, 2014, vol. 8, iss. 1, available at: http://www.cyberorient.net/article.do?articleld=8864 (accessed 14 December 2020).

15. Abdo D.M. Narrating Little Fatima: A Picture is Worth 1001 Tales. «Multiple Critique» in Fatima Mernissi's Dreams of Trespass: Tales of a Harem Girlhood. Image [\&] Narrative [e-journal], 2007, vol. 19, available at: http://www.imageandnarrative.be/ inarchive/autofiction/abdo.htm (accessed 18 January 2021).

16. Peterson K. Performing Piety and Perfection: The Affective Labor of Hijabi Fashion Videos. CyberOrient, 2016, vol. 10, iss. 1, available at: http://www.cyberorient.net/ article.do?articleld=9759 (accessed 18 November 2016).

17. Dijk Van T. Discourse and power: representation of dominance in language and communication. Moscow, Book House «LIBROKOM», 2013.

18. Yacoobi S. «How I Stopped the Taliban from Shutting Down My School», available at: https://www.ted.com/talks/sakena_ yacoobi_how_i_stopped_the_taliban_from_shutting_down_my_school/transcript?language=en\#t-136180 (accessed 18 November 2020).

19. Basij-Rasikh S. "Dare to Educate Afghan Girls», available at: https://www. youtube.com/watch?v=Ka70-Hb1wFE (accessed 08 January 2021). 